0,05) nghĩa là khoảng cách đọc sau sử dụng kính phóng đại tăng thì tốc độ đọc với kính cũng tăng.

Chọn màu sắc màn hình sẽ giúp cho bệnh nhân đọc tốt nhất, trong nhóm bệnh nhân nghiên cứu, có tới 44 bệnh nhân chọn nền trắng chữ đen $(55,0 \%)$, sau đó có 34 bệnh nhân $(42,5 \%)$ chọn nền đen chữ trắng, chỉ có 2 bệnh nhân chọn nền đen chữ vàng $(2,5 \%)$, không có bệnh nhân ( $0 \%)$ nào chọn nền xanh chữ trắng hay nền vàng chữ xanh, tuy nhiên sự lựa chọn màu sắc màn hình không liên quan đến mức độ thị lực tương phản của các bệnh nhân, kết quả của chúng tôi cũng phù hợp với tác giả Zabel.

Tuy nhiên, tác giả Ehrlich và Sanberg chứng minh rằng bệnh nhân võng mạc sắc tố đọc tốt hơn với màn hình nền đen chữ trắng còn tác giả Jacobs lại cho rằng sự lựa chọn màu sắc màn hình là sở thích chủ quan của từng cá nhân.

\section{KẾT LUÂN}

So với kính phóng đại trợ thị gân cho người khiếm thị, máy MVHD cho thị lực nhìn gần, khoảng cách đọc và tốc độ đọc cải thiện hơn hẳn.

\section{TÀI LIẸU THAM KHẢO}

1. Carmen, W. (2015) Video magnifiers, Teaching students with visual impairments, teachingvisuallyimpaired.com.

2. Carvalho, K. M. (2004). Causes of low vision and use of optical aids in the elderly, Rev. Hosp. Clin. Fac. Med. S. Paulo, 59(4), 157-60.

3. Chia-Yun Li, M. D. (2002). Low vision and Methods of Rehabilitation: A Comparison between the Past and Present. Chang Gung Med J, 25, 153-61.

4. Harvey, W. J. (2004). Electronic low vision aids, a new image for the visually impaired, Optical, 227.

5. Margrain, T. H. (2000). Helping blind and partially sighted people to read: the effectiveness of low vision aids, BJO, 84(8), 919-21.

6. Nguyễn Xuân Nhung (2009). Improvement of reading speed after providing of low vision aids in patients with age - related macular degeneration, Acta Ophthalmol, 87, 849-53.

7. Owsley, C. , Lee, P. P. (2009). Characteristics of low vision rehabilitation services in United States, Arch Ophthalmol, 127 (5), 681- 89.

8. Sandberg, M. A. , Gaudio A. R. (2006). Reading speed of patients with advanced retinitis pigmentosa or choroideremia, Retina, 26(1), 80-8.

\title{
ĐÁNH GIÁ TÁC DUNG KHÔNG MONG MUỐN CỦA GÂY TÊ TỦY SỐNG BẰNG BUPIVACAIN KẾT HỢP VỚI CÁC LIỀU MORPHIN KHÁC NHAU TRONG PHẪU THUÂTT CHẤN THƯƠNG CHI DƯớI
}

\author{
Dương Đức Phúc*, Công Quyết Thắng**, Lư Quang Thùy***
}

\section{TÓM TĂT}

Mục tiêu: So sánh tác dụng không mong muốn của GTTS bằng $8 \mathrm{mg}$ bupivacain $0.5 \%$ kết hợp với $100 \mathrm{mcg}, 200 \mathrm{mcg}, 300 \mathrm{mcg}$ morphin trong phẫu thuật chấn thương chi dưới tại bệnh viện Quân Y 105 từ tháng 11/2018 đến tháng 04/2019. Phương pháp nghiên cứu: Thử nghiệm lâm sàng, tiến cứu, có nhớm so sánh. Bệnh nhần được chia vào 03 nhóm ngẫu nhiên: Nhóm I gồm 40 bệnh nhân được GTTS bằng bupivacain liêu $8 \mathrm{mg}$ kểt hợp với morphin $0,10 \mathrm{mg}$. Nhóm II gồm 40 bệnh nhân được GTTS bằng bupivacain liều $8 \mathrm{mg}$ kết hợp với morphin 0,20mg. Nhóm III gồm 40 bệnh nhân được GTTS bằng bupivacain liều $8 \mathrm{mg}$ kết hợp với morphin $0,3 \mathrm{mg}$. Kết quả nghiên cứu: Sư thay đổi về mạch và huyết áp cũng như các thay đối về hô hấp: $\mathrm{SpO} 2$, tân số thở tại

*Bệnh viện Quân Y 105,

**aai họ Y Hà Nội

***Bệnh viện Việt Đức

Chịu trách nhiệm chính: Dương Đức Phúc

Email: duongducphuc@gmail.com

Ngày nhận bài: 14.12 .2020

Ngày phản biện khoa học: 26.01.2021

Ngày duyệt bài: 10.2.2021 các thời điểm nghiên cứu không nhiều, trong giới hạn bình thường và không có sư khác biêt giữa ba nhóm với $p>0,05$. Các tác dụng khác như bí tiểu, nôn, rét run, đau đâu không có sự khác biệt giữa 3 nhóm. Kết luận: Liều dùng morphin giảm đau: nên dùng liều $0,3 \mathrm{mg}$ vì tác dung không mong muốn không có sư khác biệt so với liều $0,2 \mathrm{mg}$ hay $0,1 \mathrm{mg}$ mà tác dụng vồ cảm và giảm đau tốt hơn.

Tư khóa: gây tê tủy sông, bupivacaine, morphin

\section{SUMMARY}

EVALUATE THE SIDE EFFECTS OF SPINAL ANESTHESIA BY BUPIVACAIN COMBINED WITH DIFFERENT MORPHIN DOSES IN LOWER EXTREMITY SURGERY

Objective: To compare the side effects of spinal anesthesia by $8 \mathrm{mg}$ bupivacaine $0.5 \%$ combined with $100 \mathrm{mcg}$, 200mcg, $300 \mathrm{mcg}$ morphine in lower extremity surgery at 105 Military Hospital from November 2018 to April 2019. Method: prospective randomized controlled trial interventional study. The patients were divided into three random groups: Group I included 40 patients who received $8 \mathrm{mg}$ bupivacaine combined with $0,1 \mathrm{mg}$ morphine. Group II consisted of 40 patients who received $8 \mathrm{mg}$ bupivacaine combined with 0,2 mg morphine. Group 
III consisted of 40 patients who received $8 \mathrm{mg}$ bupivacaine combined with $0,3 \mathrm{mg}$ morphine. Results: Pulse rate and blood pressure changes as well as respiratory changes: $\mathrm{SpO} 2$, respiratory rate at the time performing the study was not remarkable in normal range and there was no difference in three groups with $p>0,05$. Other effects such as urinary retention, vomiting, trembling and headache did not differ between 3 groups. Conclusions: Analgesia morphine dose: should apply dose of $0,3 \mathrm{mg}$ due to having the same side effects as doses of $0,2 \mathrm{mg}$ or $0,1 \mathrm{mg}$ but more effective analgesia.

Key words: spinal anesthesia, bupivacaine, morphine

\section{I. ĐĂT VẤN ĐỀ}

Gây tê tủy sống (GTTS) là phương pháp vô cảm chủ yếu trong phẫu thuật chi dưới. GTTS có ưu điểm là kỹ thuật đơn giản, giá thành thấp, hậu phẫu nhẹ nhàng và giảm đau sau mổ tốt. Bupivacain là thuốc tê có đặc điểm khởi tê nhanh, tác dụng kéo dài, cường độ mạnh, mềm cơ bụng và chi dưới kéo dài 2-5h nhưng có tác dụng không mong muốn là tụt huyết áp, mạch chậm... Các nhà gây mê luôn mong muốn giảm tác dụng phụ của thuốc tê để đảm bảo an toàn cho bệnh nhần nhưng vẫn đảm bảo vô cảm cho phẩu thuật. Để đáp ứng yêu cầu này cách tốt nhất là giảm liều thuốc tê và phối hợp với thuốc giảm đau khác. Một trong các thuốc có tác dụng hiệp đồng với thuốc tê là các thuốc giảm đau nhóm opiat: morphin, fentanyl, pethidin, sufetanyl... Hiện nay trên thế giới việc nghiên cứu phối hợp thuốc tê với morphin để vô cảm cho mổ và kéo dài thời gian giảm đau sau mổ đã mang lại hiệu quả cao. Katsuyuki Terajima và cộng sự cho rằng: phối hợp bupivacain với morphin trong GTTS để kéo dài thời gian giảm đau sau mổ, đơn giản, dễ thực hiện ở các bệnh viện và rẻ tiên hơn các kỹ thuật giảm đau khác đang sử dụng [1]. Nhưng các tác dụng phụ xảy ra ở các nhóm có sự khác biệt. Ở Việt Nam, đã có nhiêuu đề tài nghiên cứu phối hợp bupivacain với morphin để GTTS trong mổ chấn thương chi dưới mang lại kết quả tốt. Tuy nhiên việc sử dụng morphin trong GTTS để phẫu thuật chấn thương chi dưới với liều bao nhiêu là tối ưu để đạt hiệu quả vô cảm trong phẫu thuật, giảm đau sau mổ kéo dài, hạn chế các tác dụng không mong muốn còn ít báo cáo chính thức. Chính vì vậy chúng tôi nghiên cứu đề tài: "Đánh giá tác dụng không mong muốn của GTTS bằng bupivacain kết hợp với các liều morphin khác nhau trong phẫu thuật chấn thương chi dưới"với mục tiêu sau: So sánh tác dụng không mong muốn của GTTS bằng 8mg bupivacain 0.5\% kêt hợp với 100mcg, 200mcg, 300mcg morphin trong phẫu thuật chấn thương chi dưới.

\section{II. ĐỐI TƯợNG VÀ PHƯƠNG PHÁP NGHIÊN CỨU}

2.1 Đối tượng nghiên cứu: Bênh nhân được chọn khi có đủ các tiêu chuẩn: BN có tinh thần tỉnh táo, đồng ý tham gia nghiên cứu. Tuổi từ 16 - 65 tuổi. Tình trạng sức khỏe ASA I, II. Cân nặng trên $40 \mathrm{~kg}$. Không có chống chỉ định với GTTS. Không có dị ứng với bupivacain và morphin. Bệnh nhân bị loại trừ khỏi nghiên cứu khi: BN có khó khăn trong giao tiếp, mắc bệnh động kinh hay tâm thần. Tiền sử hay hiện tại nghiện ma túy. BN từ chối tham gia nghiên cứu. Các trường hợp có tai biến, biến chứng về phẫu thuật và gây mê trong và sau mổ: chảy máu nhiều, tụt huyết áp nặng, suy hô hấp... Dự kiến mổ kéo dài > 150 phút. BN không đồng ý tiếp tục tham gia nghiên cứu.

2.2 Địa điểm và thời gian nghiên cứu: Đề tài được thực hiện tại khoa Gây mê hồi sức Bệnh viện Quân y 105. Tiến hành từ T11/2018 đến T4/2019.

2.3 Phương pháp nghiên cứu: Thử nghiệm lâm sàng, tiến cứu, có nhóm so sánh.

Chọn ngẫu nhiên theo phương pháp bốc thăm, thăm gồm 3 nhóm bằng nhau. Mỗi bệnh nhân sẽ tương ứng với một lân bắt thăm, bắt được thăm nào thì xếp vào nhóm đó và thực hiện đúng theo phương pháp đó. Mỗi nhóm được tiến hành nghiên cứu và thu thập số liệu như nhau. Nhóm I gồm 40 bệnh nhân được GTTS bằng bupivacain liều $8 \mathrm{mg}$ kết hợp với morphin $0,10 \mathrm{mg}$. Nhóm II gồm 40 bệnh nhân được GTTS bằng bupivacain liêu $8 \mathrm{mg}$ kết hợp với morphin 0,20mg. Nhóm III gồm 40 bệnh nhân được GTTS bằng bupivacain liều $8 \mathrm{mg}$ kết hợp với morphin 0,3mg. Tiêu chuẩn đánh giá: Rối loạn tuần hoàn: Khi nhịp tim dưới 50 lần/phút. Khi HA tối đa tụt $20 \%$ so với HA tối đa. Đánh giá là có rối loạn về hô hấp: Khi bệnh nhân thở chậm < 10 lần/phút hoặc $\mathrm{SpO}_{2}<90 \%$. Tiêu chuẩn đánh gía nôn và buồn nôn theo Alfel C [2]. Mức độ bí tiểu theo Aubrun $F$ [3]. Mức độ ngứa theo Suhattaya [4].

Thời điểm đánh giá: Theo dõi và đánh giá liên tục trên máy mornitor sự thay đổi về huyết động, hô hấp và các yếu tố khác tại các thời điểm trong mổ sau:

\begin{tabular}{|c|c|c|c|}
\hline $\mathbf{H}_{\mathbf{0}}$ & Trước khi gây tê & $\mathbf{H}_{\mathbf{3 0}}$ & Sau khi gây tê 30 phút \\
\hline $\mathbf{H}_{\mathbf{1}}$ & Ngay sau khi gây tê & $\mathbf{H}_{\mathbf{4 0}}$ & Sau khi gây tê 40 phút \\
\hline $\mathbf{H}_{\mathbf{5}}$ & Sau khi gây tê 5 phút & $\mathbf{H}_{\mathbf{5 0}}$ & Sau khi gây tê 50 phút \\
\hline
\end{tabular}




\begin{tabular}{|c|c|c|c|}
\hline $\mathbf{H}_{\mathbf{1 0}}$ & Sau khi gây tê 10 phút & $\mathbf{H}_{\mathbf{6 0}}$ & Sau khi gây tê 60 phút \\
\hline $\mathbf{H}_{\mathbf{1 5}}$ & Sau khi gây tê 15 phút & $\mathbf{H}_{\mathbf{9 0}}$ & Sau khi gây tê 90 phút \\
\hline $\mathbf{H}_{\mathbf{2 0}}$ & Sau khi gây tê 20 phút & $\mathbf{H}_{\mathbf{1 2 0}}$ & Sau khi gây tê 120 phút \\
\hline $\mathbf{H}_{\mathbf{2 5}}$ & Sau khi gây tê 25 phút & $\mathbf{H}_{\mathbf{K T}}$ & Kết thúc cuộc mố \\
\hline
\end{tabular}

2.5 Xử lý số liệu: Số liệu thu được xử lý bằng toán thống kê y học bằng phần mềm SPSS 16.0 giữa các nhóm gây tê bằng bupivacain kết hợp với morphin ở các liều khác nhau.

III. KẾT QUẢ NGHIÊN CỨU

3.1 Đặc điểm chung của 3 nhóm nghiên cứu:

Bảng 3.1. Đặc điểm về tuổi, chiều cao, cân nặng của ba nhóm nghiên cứu

\begin{tabular}{|c|c|c|c|c|}
\hline \multicolumn{2}{|c|}{ Thông số } & Nhóm I $(n=40)$ & Nhóm II $(n=40)$ & Nhóm III $(n=40)$ \\
\hline \multirow{2}{*}{$\begin{array}{l}\text { Tuổi } \\
\text { (năm) }\end{array}$} & $X \pm S D$ & $39,05 \pm 15,59$ & $38,48 \pm 13,65$ & $40,30 \pm 14,76$ \\
\hline & $\operatorname{Min} \div \operatorname{Max}$ & $16 \div 65$ & $16 \div 65$ & $17 \div 65$ \\
\hline \multirow{2}{*}{$\begin{array}{l}\text { Chiêu cao } \\
\text { (cm) }\end{array}$} & $\mathrm{X} \pm \mathrm{SD}$ & $163,18 \pm 4,51$ & $161,83 \pm 4,24$ & $163,63 \pm 3,89$ \\
\hline & $\operatorname{Min} \div \operatorname{Max}$ & $156 \div 170$ & $155 \div 168$ & $158 \div 170$ \\
\hline \multirow{3}{*}{$\begin{array}{c}\text { Cân nă̆ng } \\
(\mathrm{kg})\end{array}$} & $\mathrm{X} \pm \mathrm{SD}$ & $57,40 \pm 5,48$ & $59,28 \pm 6,09$ & $57,25 \pm 6,93$ \\
\hline & $\operatorname{Min} \div \operatorname{Max}$ & $45 \div 65$ & $50 \div 69$ & $45 \div 68$ \\
\hline & P & $\mathrm{p} 1>0,05$ & p2 $>0,05$ & p3 >0,05 \\
\hline
\end{tabular}

(p so sánh giữa ba nhóm, $\mathrm{p} 1$ so sánh giữa nhómI và nhóm II, p2 so sánh giữa nhóm I và nhóm III, p3 so sánh giữa nhóm II và nhóm III)

Nhận xét: Về tuổi, chiều cao, cân nặng, của ba nhóm tương đương và khác biệt không có ý nghĩa thống kê với $p>0,05$. Như vậy các đối tượng ở các nhóm là gần giống nhau về tuổi, chiều cao, cân nặng.

3.2 Tác dụng không mong muốn lên hô hấp

Bảng 3.2. Tần số thở (lần/ phút) theo thời gian

\begin{tabular}{|c|c|c|c|c|}
\hline Thờ gian & Nhóm I $(\mathrm{n}=40)$ & Nhóm II $(\mathrm{n}=40)$ & Nhóm III $(\mathrm{n}=40)$ & $\mathbf{P}(\mathrm{p} 1, \mathrm{p} 2, \mathrm{p} 3)$ \\
\hline $\mathrm{H} 0$ & $17,86 \pm 1,63$ & $17,48 \pm 1,56$ & $17,99 \pm 1,38$ & $>0,05$ \\
\hline $\mathrm{H} 1$ & $18,07 \pm 1,71$ & $17,84 \pm 1,66$ & $17,43 \pm 1,71$ & $>0,05$ \\
\hline $\mathrm{H} 5$ & $17,83 \pm 1,15$ & $17,95 \pm 1,14$ & $18,06 \pm 1,20$ & $>0,05$ \\
\hline $\mathrm{H} 10$ & $17,86 \pm 1,70$ & $17,55 \pm 1,63$ & $17,32 \pm 1,56$ & $>0,05$ \\
\hline $\mathrm{H} 15$ & $17,79 \pm 1,21$ & $17,58 \pm 1,15$ & $17,93 \pm 1,19$ & $>0,05$ \\
\hline H20 & $17,88 \pm 1,28$ & $17,93 \pm 1,11$ & $18,09 \pm 1,09$ & $>0,05$ \\
\hline H25 & $17,97 \pm 1,08$ & $18,23 \pm 1,16$ & $18,11 \pm 1,16$ & $>0,05$ \\
\hline H30 & $17,83 \pm 1,29$ & $17,92 \pm 1,23$ & $17,87 \pm 1,34$ & $>0,05$ \\
\hline H45 & $17,69 \pm 1,04$ & $17,88 \pm 1,07$ & $18,11 \pm 1,14$ & $>0,05$ \\
\hline H60 & $18,96 \pm 1,42$ & $18,13 \pm 1,22$ & $18,18 \pm 1,27$ & $>0,05$ \\
\hline H90 & $17,11 \pm 0,67$ & $18,07 \pm 1,26$ & $18,25 \pm 1,27$ & $>0,05$ \\
\hline H120 & $17,73 \pm 1,10$ & $17,96 \pm 1,22$ & $17,89 \pm 1,79$ & $>0,05$ \\
\hline H KT & $18,47 \pm 0,49$ & $18,37 \pm 0,67$ & $18,29 \pm 0,76$ & $>0,05$ \\
\hline
\end{tabular}

Bảng 3.3. Thay đối bão hòa oxy (\%) theo thời gian

\begin{tabular}{|c|c|c|c|c|}
\hline Thời gian & Nhóm I $(\mathrm{n}=40)$ & Nhóm II $(\mathrm{n}=40)$ & Nhóm III $(\mathrm{n}=40)$ & $\mathbf{P}(\mathrm{p} 1, \mathrm{p} 2, \mathrm{p} 3)$ \\
\hline H0 & $99,05 \pm 0,88$ & $98,95 \pm 0,81$ & $98,83 \pm 0,87$ & $>0,05$ \\
\hline H1 & $98,90 \pm 0,78$ & $98,90 \pm 0,93$ & $99,05 \pm 0,90$ & $>0,05$ \\
\hline H5 & $99,00 \pm 0,88$ & $99,03 \pm 0,77$ & $99,13 \pm 0,72$ & $>0,05$ \\
\hline H10 & $99,03 \pm 0,83$ & $99,00 \pm 0,85$ & $99,03 \pm 0,83$ & $>0,05$ \\
\hline H15 & $98,90 \pm 0,90$ & $99,05 \pm 0,78$ & $99,95 \pm 0,85$ & $>0,05$ \\
\hline H20 & $99,13 \pm 0,82$ & $98,93 \pm 0,86$ & $99,15 \pm 0,83$ & $>0,05$ \\
\hline H25 & $99,05 \pm 0,81$ & $98,85 \pm 0,86$ & $98,80 \pm 0,85$ & $>0,05$ \\
\hline H30 & $98,78 \pm 0,83$ & $99,10 \pm 0,78$ & $98,85 \pm 0,83$ & $>0,05$ \\
\hline H45 & $98,95 \pm 0,81$ & $98,93 \pm 0,76$ & $98,95 \pm 0,88$ & $>0,05$ \\
\hline H60 & $99,15 \pm 0,86$ & $98,90 \pm 0,84$ & $99,00 \pm 0,88$ & $>0,05$ \\
\hline H90 & $98,90 \pm 0,87$ & $99,00 \pm 0,75$ & $98,98 \pm 0,86$ & $>0,05$ \\
\hline H120 & $99,08 \pm 0,83$ & $99,25 \pm 0,87$ & $99,08 \pm 0,73$ & $>0,05$ \\
\hline H KT & $99,08 \pm 0,79$ & $99,00 \pm 0,82$ & $99,20 \pm 0,85$ & $>0,05$ \\
\hline
\end{tabular}

(p so sánh giữa ba nhóm, p1 so sánh giữa nhómI và nhóm II, p2 so sánh giữa nhómI và nhómIII, 
p3 so sánh giữa nhóm II và nhómIII)

Nhận xét: Sau khi GTTS tần số thở trung bình và độ bão hòa oxy (SpO2) ba nhóm đều trong giới hạn bình thường tại tất cả các thời điểm nghiên cứu trong mổ. Sự khác biệt không có ý nghĩa thống kề giữa ba nhóm với $\mathrm{p}>0,05$.

\subsection{Tác dụng không mong muốn lên tuân hoàn}

Bảng 3.4. Tấn số tím (lần/phút) giữa ba nhóm nghiên cứu theo thời gian

\begin{tabular}{|c|c|c|c|c|}
\hline Thời gian & Nhóm I $(\mathrm{n}=40)$ & Nhóm II $(\mathrm{n}=40)$ & Nhóm III $(\mathrm{n}=40)$ & $\mathbf{P}(\mathrm{p} 1, \mathrm{p} 2, \mathrm{p} 3)$ \\
\hline $\mathrm{H} 0$ & $82,7 \pm 4,59$ & $81,03 \pm 4,54$ & $81,33 \pm 4,30$ & $>0,05$ \\
\hline H1 & $83,13 \pm 4,47$ & $82,1 \pm 4,45$ & $83,45 \pm 4,59$ & $>0,05$ \\
\hline H5 & $74,53 \pm 4,31$ & $74,18 \pm 4,29$ & $74,8 \pm 4,21$ & $>0,05$ \\
\hline H10 & $73,95 \pm 4,42$ & $72,73 \pm 3,81$ & $73,85 \pm 4,48$ & $>0,05$ \\
\hline H15 & $83,13 \pm 4,93$ & $82,88 \pm 4,93$ & $82,98 \pm 4,41$ & $>0,05$ \\
\hline H20 & $82,6 \pm 4,34$ & $83,13 \pm 4,71$ & $82,25 \pm 4,58$ & $>0,05$ \\
\hline H25 & $83,18 \pm 4,21$ & $82,43 \pm 4,55$ & $83,08 \pm 4,19$ & $>0,05$ \\
\hline H30 & $82,55 \pm 4,82$ & $83 \pm 4,08$ & $82,88 \pm 4,56$ & $>0,05$ \\
\hline H45 & $83,08 \pm 4,58$ & $82,88 \pm 4,12$ & $83,08 \pm 4,51$ & $>0,05$ \\
\hline H60 & $82,8 \pm 3,78$ & $83,03 \pm 4,03$ & $83,05 \pm 4,44$ & $>0,05$ \\
\hline H90 & $83,1 \pm 4,99$ & $83,5 \pm 4,60$ & $82,25 \pm 4,24$ & $>0,05$ \\
\hline H120 & $82,8 \pm 4,64$ & $83,15 \pm 4,69$ & $83,03 \pm 4,13$ & $>0,05$ \\
\hline H KT & $82,83 \pm 4,62$ & $83,08 \pm 5,09$ & $83,2 \pm 4,26$ & $>0,05$ \\
\hline
\end{tabular}

Bảng 3.5. Tỷ lệ bệnh nhân bị tụt huyết áp giữa ba nhóm nghiên cứu.

\begin{tabular}{|c|c|c|c|c|c|c|}
\hline \multirow{2}{*}{ Huyết áp } & \multicolumn{2}{|c|}{ Nhóm I $(\mathrm{n}=40)$} & \multicolumn{2}{c|}{ Nhóm II $(\mathrm{n}=40)$} & Nhóm III $(\mathrm{n}=40)$ \\
\cline { 2 - 7 } & $\mathbf{n}$ & $\mathbf{\%}$ & $\mathbf{n}$ & $\mathbf{\%}$ & $\mathbf{n}$ & $\mathbf{\%}$ \\
\hline Tụt huyết áp & 6 & 15 & 8 & 20 & 5 & 12,5 \\
\hline Không tụt huyết áp & 34 & 85 & 32 & 80 & 35 & 87,5 \\
\hline p & \multicolumn{5}{|c|}{$\mathrm{p}>0,05$} \\
\hline
\end{tabular}

Nhận xét: Giữa ba nhóm nghiên cứu, sự thay đổi tần số tim ở các thời điểm không có sự khác nhau với $p>0,05$. Tỷ lệ bệnh nhân tụt HA sau gây tê tủy sống giữa ba nhóm nghiên cứu khác nhau không có ý nghĩa thống kê với $p>0,05$.

\subsection{Các tác dụng không mong muốn khác}

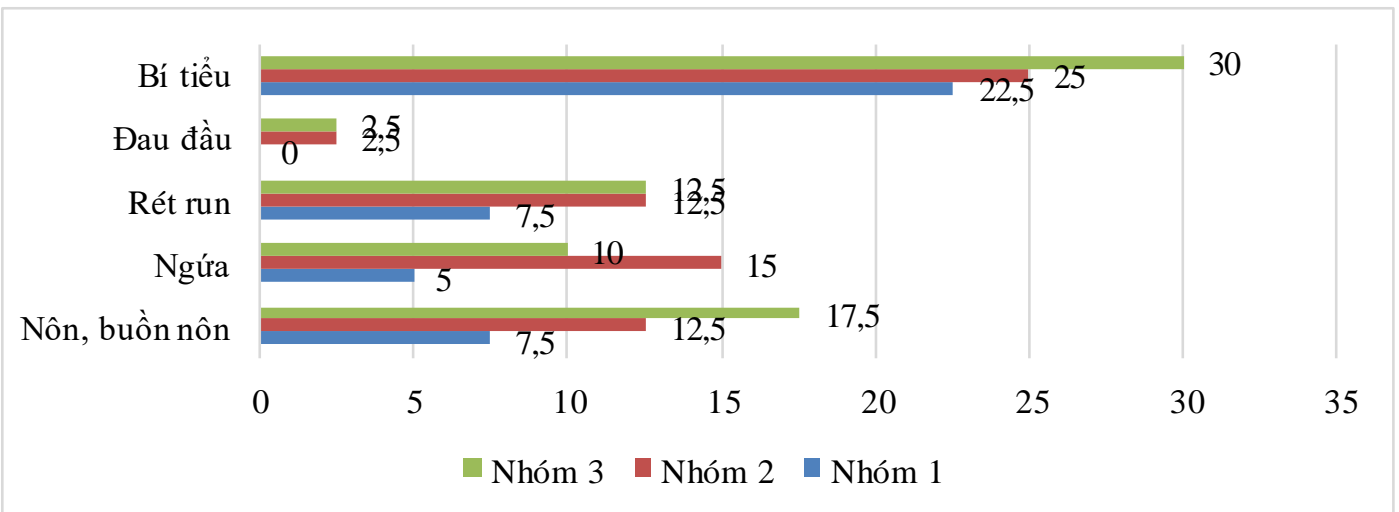

Biểu đồ 3.1. Tỷ lệ bệnh nhân mắc các tác dụng không mong muốn trong và sau phẫu thuật (\%) Nhận xét: Không có sự khác biệt giữa 3 nhóm về tác dụng phụ với $p<0,05$.

\section{BÀN LUÂN}

4.1 Tác dụng phụ lên hô hấp, tuần hoàn: Morphin tác dụng ức chế trung tâm hô hấp ở hành não làm giảm sự nhạy cảm của trung tâm này với tăng $\mathrm{CO} 2$ và giảm $\mathrm{O} 2$ [26]. Chúng tôi tiến hành gây tê tủy sống kết hợp với morphin trên 120 bệnh nhân mổ chấn thương chi dưới thấy tại tất cả các thời điểm không có bệnh nhân nào suy hô hấp, tần số thở trung bình của ba nhóm từ 17-19l/phút. Độ bão hòa oxy mao mạch (SpO2) ổn định ở ba nhóm > 98\% và ở ba nhóm không có sự khác biệt giữa các nhóm nghiên cứu ở các thời điểm với $\mathrm{p}>0,05$. Theo An Thành Công nghiên cứu liều $0,3 \mathrm{mg}$ morphin tủy sống kết quả giảm đau tốt trong 24 giờ đầu và không có trường hợp nào bị suy hô hấp trong và sau 
mổ [5]. Suy hô hấp, nhất là suy hô hấp muộn (6 đến 8 giờ sau mổ) biến chứng nguy hiểm khi sử dụng opioid tủy sống. Chính vì vậy việc theo dõi thường xuyên các chỉ số hô hấp là rất quan trọng. Những bệnh nhân trong nhóm nghiên cứu của chúng tôi đều có tình trạng sức khỏe tốt ASA I, ASA II,tuổi từ 16 đênn 65. Những bênh nhân này đều được theo dõi bằng morniter về các chỉ số sinh tồn: Mạch, $H A$, điện tin, tần số thở và SpO2, được thở oxy trước, trong, sau mổ và tại phòng hậu phẫu 6 đến 8 giờ sau mổ với đội ngũ nhân viên y tế được đào tạo bài bản về chăm sóc bệnh nhân sau mổ thường xuyên túc trực tại phòng hậu phẫu. Như vậy khi kết hợp morphin các liều $0,1 \mathrm{mg} ; 0,2 \mathrm{mg} ; 0,3 \mathrm{mg}$ trong GTTS bệnh nhân không những được giảm đau tốt mà còn ổn định về tần số thở và $\mathrm{SpO}$. Với số liệu cho thấy trước khi gây tê nhịp tim của 3 nhóm lần lượt là: $82,05 \pm 4,59 ; 83,53 \pm 4,84 ; 82,45 \pm$ 5,11 , các số liệu này cho thấy tân số tim trước khi gây tê ở cả 3 nhóm là gần như nhau. Kết quả của nghiên cứu này cũng giống với các kết quả của các tác giả trong nước như Đỗ Văn Lợi, Nguyễn Hoàng Ngọc [6], [7]. Tỷ lệ bệnh nhân có tụt HA ở cả 3 nhóm nghiên cứu là gần như nhau, điều này cho thấy khi sử dụng kết hợp morphin với liều sử dụng trong nghiên cứu này có tỷ lệ người bệnh bị tưt $H A$ giống nhau. Tut $H A$ trong GTTS ở nghiên cứu này thường gặp ở những $B N$ kết xương đùi vừa thiếu máu trước mổ vừa mất máu trong mổ. Như vậy nguyên nhân gây tụt huyết áp trên $20 \%$ trong nghiên cứu của chúng tôi chủ yếu do mất máu trong mổ và thứ yếu do ức chế giao cảm cao. Do đó để đảm bảo không tụt huyết áp cần bổ sung dịch và máu cho $B N$ môt cách đầy đủ, kịp thời thời theo PVC nhằm đảm bảo khối lượng tuần hoàn và cho thêm thuốc co mạch nểu cần. Các BN trong nghiên cứu của chúng tôi đã được điều trị kịp thời nên thời gian xảy ra tưt huyết áp ngắn, huyết áp lên ngay và nhanh chóng trở lại ổn định trong giới hạn bình thường đến hết cuộc mố. Kết quả của nghiên cứu này cũng gần tương tự với các kết quả của các tác giả Đố Văn Lợi, Phan Anh Tuấn [6], [8].

4.2 Các tác dụng không mong muốn khác: Tỷ lệ nôn, buồn nôn ở 3 nhóm không có sự khác biệt, nhóm I: 7,5\%; nhóm II: 12,5\%, ở nhóm III còn có $17,5 \%$, không có trường hợp nào nôn nặng ở cả 3 nhóm. Nghiên cứu của Michelle Wheeler[9] cho thấy tỷ lệ nôn-buồn nôn sau GTTS bằng morphin là $17,1 \%$ còn nhóm tiêm morphin tĩnh mạch có tỷ lệ $28,2 \%$. Katsuyki Terajima và Hidetaka Onodera [1], nghiên cứu phối hợp 0,2mg morphin với bupivacain GTTS để mổ lấy thai cho 22 trường hợp, thấy tỷ lệ nônbuồn nôn là: $14 \%$. Nghiên cứu của chúng tôi cũng không có sự khác biệt giữa 3 nhóm về tác dụng phụ bí tiểu. Kết quả này tương tự với nghiên cứu của các tác giả trong và ngoài nước. Theo Phan Anh Tuấn dùng $0,1 \mathrm{mg}$ morphin kết hợp với bupivacain gây tê tủy sống tỷ lệ bí tiểu gặp là $3,1 \%$ [8]. Theo Đố Văn Lợi với liều $0,15 \mathrm{mg}$ morphin gặp 3,3\%, [6]. Theo Michelle Wheeler [9] nghiên cứu GTTS ơ 90 trường hợp có 32 trường hợp bí tiểu (35,6\%). Ngứa khi dùng morphin tê tủy sống được giải thích do giải phóng histamin, một phần do morphin gắn trực tiếp trên receptor vùng hành não ngứa là do tác dụng của các chất thuốc phiện khi tiêm bắp cũng thấy nhưng qua tủy sống và NMC hay gặp hơn. Trong nghiên cứu của chúng tôi tất cả các bệnh nhân đều là ngứa nhẹ thoáng qua không phải điều trị và tự khỏi.

\section{KẾT LUẬN}

- Sự thay đổi về mạch và huyết áp tại các thời điểm nghiên cứu không nhiêu, trong giới hạn bình thường và không có sự khác biệt giữa ba nhóm với $p>0,05$. Ít ảnh hưởng lên hô hấp thể hiện ở sự ổn đinh về tần số thở và $\mathrm{SpO} 2$ trong quá trình phẫu thuật của cả ba nhóm nghiên cứu, sự khác biệt khồng có ý nghĩa thống kê với $p>0,05$.

- Tỷ lệ nôn-buồn nôn ở nhóm I là: 7,5\%, nhóm II là $12 \%$ và nhóm III $17,5 \%$, sự khác biệt không có ý nghĩa thống kê với $p>0,05$. Tỷ lệ bí tiểu ở nhóm I là: $22,5 \%$, nhóm II là $25 \%$ và nhóm III là 30\%, sự khác biệt không có ý nghĩa thống kê với $p>0,05$. Tỷ lệ ngứa nhóm I là $5 \%$, nhóm II là $15 \%$ và nhóm III là $10 \%$, sự khác biệt không có ý nghĩa thống kê với p>0,05.

\section{TÀI LIẸU THAM KHẢO}

1. Katsuyki Terajima, Hidetaka Onodera, Masao Kobayashi, Hiroko Yamanaka, Takashi Ohno, Swiichi Konuma and Ruo Ogawa (2003). "Effcacy of Intrathecal Morphine for analgesia Following Elective Cesarean Section: comparison with Previous Delivery", J Nippon Med Sch 70 (4).

2. Apfel C, Roewer N, Korttila K (2002). "How to study postoperative nausea and vomiting", Acta Anaesthesiol Scand, 46:921-928.

3. Aubrum F, Benhamou D (2000), "Attitude practique pour laprise, en charge de le douleur", Ann Fr Anesth Réanin 19, pp. 137-157.

4. Suhattaya Boonmak (2007), "Combarison of intrathecal morphin plus PCA and PCA alone for postoperative analgasia after kidney surgery", Journal of the Medical Association of Thailand. 90(6), pp.1143-1149

5. An Thành Công (2011), "Đánh giá tác dụng giảm 
đau dự phòng sau mổ tầng bụng trên bằng phương pháp tiêm morphine tủy sống", Luận văn thăc sỹ y học, Trường Đại học Y Hà Nội.

6. Đố Văn Lơơi (2007): "N̉ghiên cứu phối hợp Bupivacain với Morphin hoặc Fentanyl trong gây tê tuyy sống để mổ lấy thai và giảm đau sau mô", Luân văn thac sỹ y hoc. Trường đai hoc Y Hà Nôi.

7. Nguyễn Hoàng Ngọc (2010) "Đánh giá tác dụng vố cảm và giảm đau sau mổ trong mô lây thai của gây tê tủy sống bằng bupivacain kết hợp morphin ở các liêu khác nhau", Luận văn bác sỹ chuyên khoa cấp 2, Trường Đai hợ Y Hà Nôi.

8. Phan Anh Tuấn (2008), "Đánh giá tác dụng của Gây tê tủy sống bằng bupivacain kết hợp morphin và bupivacain kết hợp fentanyl trong mổ chi dưới", Luânn văn thạc sỹ y học, Học viện Quân y.

9. Michelle Wheeler, Gary M, Oderda (2002). "Adverse events associated with postoperative opioid analgesia: A systematic review", The Journal of Pain, Volume 3 Number 3:159-180.

\section{VIÊM TUY CẤP DO RƯỚU VÀ DO TĂNG TRIGLYCERIDE MÁU: MỨC Độ NẶ̂ VÀ KẾT CỤC LÂM SÀNG}

\section{Võ Duy Thông ${ }^{1,2}$, Nguyễn Thị Mộng Trinh ${ }^{3}$, Hồ Tấn Phát ${ }^{2}$}

\section{TÓM TẮT}

Mục tiêu: Khảo sát mức độ nặng và kết cục lâm sàng giữa viêm tuy cấp (VTC) do rượu và do tăng triglyceride (TG) mau. Đối tượng và phương pháp: Nghiên cứu cắt ngang mô tà có phân tích, so sánh mức đô năng và kết cưc giữa viêm tuy cấp do tăng TG và do rươu. Bênh nhẩn (BN) đủ 18 tuổi trở lên, thỏa tiêu chuẩn chẩn đoán của VTC. Đánh giá mức độ năng của VTC dưa vào bảna phân đô Atlanta hiêu chinh 2012, BISAP, thanq điểm CTSI và SIRS tai thời điểm nhâp viên. Kết cuc lâm sàna aồm biến chứna suy một hoặc nhiều cơ quan, nhập ICU và tử vong. Kết quả: Tuổi trung bình trong nghiên cứu là 39,2 9,7 . Phần lớn bệnh nhân là nam, với tỷ lệ nam/nữ là $3,5 / 1$. Không có sự khác biệt của tiền cằn VTC, đái tháo đường và tăng huyết áp giữa hai nhóm. BN VTC do TG có mức độ nặng nhiêu hơn so với nhóm BN VTC do rươu (41, $6 \%$ so với $9,4 \%, p<0,001)$. Thang điểm SIRS và CTSI có sự khác biệt có ý nghĩa thống kê giữa hai nhóm VTC do TG và do rượu $(p=0,0058$ và $\mathrm{p}=0,0027)$. Tỷ lệ nhập ICU và thời gian nằm viện của nhóm VTC do TG có tỷ lệ cao hơn so với VTC do rượu ( $p=0,038$ và $p=0,042$ ). Kết luận: VTC do TG so với VTC do rượu có mức độ viêm tuỵ nặng hơn, có thời gian nằm viên dài hơn.

Tư khóa: viểm tuy cấp, triglyceride, rượu

\section{SUMMARY}

\section{ALCOHOL-INDUCED AND HYPERTRIGLYCERIDEMIA-INDUCED ACUTE PANCREATITIS: SEVERITY AND CLINICAL OUTCOMES}

Objective: To investigate the severity and clinical outcomes of patients with alcohol-induced and hypertriglyceridemia-induced acute pancreatitis (AP).

${ }^{1}$ Đại học Y Dược Thành phố Hồ Chí Minh

²Bênh viện Chợ Rẫy, Thành phố Hồ Chí Minh

${ }^{3}$ Trường Đại hoc Trà Vinh

Chịu trách nhiệm chính: Võ Duy Thông

Email: duythong@ump.edu.vn

Ngày nhận bài: 22.12.2020

Ngày phản biên khoa họ: 26.01.2021

Ngày duyệt bài: 11.2.2021
Methods: Descriptive cross-sectional study was conducted to compare the severity and outcomes between acute pancreatitis due to hypertriglyceridemia and alcohol. Patients aged 18 years or older, diagnosed with AP were included in this study. AP severity was assessed based on 2012 adjusted Atlanta scale, BISAP, CTSI and SIRS scale at the time of admission. Clinical outcomes included one or more organ failure complications, ICU admission and death. Results: The mean age of patients was $39.2 \pm 9.7$. Most of patients were men with the male/ female ratio of 3.5/1. There was no differences regarding a history of $\mathrm{AP}$, diabetes and hypertension between the two groups. Patients with hypertriglyceridemia-induced AP were more severe than alcohol-induced AP patients (41.6\% vs. 9.4\%, p $<0.001)$. SIRS and CTSI scores were statistically significant different between the two groups ( $p=$ 0.0058 and $p=0.0027)$. The rate of ICU admission and the length of hospitalization of hypertriglyceridemia-induced AP were higher than that in alcohol-induced AP patients $(p=0.038$ and $p=$ 0.042). Conclusion: Patients with hypertriglyceridemia-induced AP are more severe have longer hospital stay.

$$
\text { Keywords: }
$$
acute hypertriglyceridemia-induced, alcohol-induced.

\section{I. ĐĂT VẤN ĐỀ}

Viêm tụy cấp (VTC) là một trong những bệnh lý đường tiêu hóa thường gặp nhất ở khoa cấp cứu của các bệnh viện, bệnh nhân (BN) thường nhập viện với bênh cảnh đau bụng cấp tính, diễn tiến từ nhẹ đển nặng và có thể đe dọa tính mạng của người bệnh. Tỷ lệ tử vong chung của VTC từ $1-5 \%$. VTC thể nhe, thường tư giới hạ và hồi phục trong vòng từ 3 đến 5 ngày có tỷ lê tử vong dưới $1 \%$. Trong khi đó, VTC thể nặng có tỷ lệ tử vong có thể lên đến 30 đến $40 \%$ [1]. Ngày nay với sự tiến bộ của các phương tiện kỹ thuật, sự cập nhật của các khuyến cáo và hướng dần trong điêu trị VTC, việc chẩn đoán, tiên lượng và theo dõi BN đã có nhiều thuận lợi hơn. Cớ chế gây ra VTC do các nguyên nhân khác 